\title{
Sustainability of micro-entrepreneurs' business: the role of their behavior model on Internet- platforms in the context of sharing economy challenges
}

\author{
Pavel Glukhikh* \\ Ural State University of Economics, 8 March Str., 62, 620144 Ekaterinburg, Russia
}

\begin{abstract}
New entrepreneurs' behavior models with controversial consequences are forming on Internet-platforms of sharing economy. The aim of the article is to reveal theoretical and methodological approaches to behavior model of micro-entrepreneurs in the market of Internet-platforms and evaluate the consequences for sustainability of micro-entrepreneurs and economy. The dialectical method, cause-and-effect analysis, deduction and induction, analysis and synthesis were used. The research of sharing economy is being in active progress, however, the consequences for microentrepreneurs have not been estimated properly yet. A separate complex research is needed to assess the contribution of micro-entrepreneurs into achievement of development goals for national business.
\end{abstract}

\section{Introduction}

The significance of the research into micro-entrepreneurs' behavior on Internet-platforms in the context of challenges of the sharing economy is composed of the following factors. The development of the sharing economy is a significant trend that cannot be ignored. Initially, the idea of a sharing economy is based on goods, including used ones, which are delivered from one person, who no longer needs them, to another, who needs them. The volume of the Russian market for the sharing economy, according to the estimates of the Russian Association for Electronic Communications, amounted 511 billion rubles or $0.52 \%$ of GDP in 2018 . The growth in 2018 was about $30 \%$ compared to the results of 2017 . C2C sales are the first branch of the sharing economy in Russia in terms of volume (370 billion rubles in 2018 , or $72 \%$ of the volume of transactions in the sharing market). The second place belongs to the industry of the online freelance exchange (98 billion rubles, or $19 \%$ of the sharing market). Also, transport (carpooling - 13.7 billion rubles, car sharing -13 billion rubles), rental of premises (residential -9.8 billion rubles and office (co-working) -5.7 billion rubles), crowd-funding (co-financing - 0.4 billion rubles), rental of things $(0.2$ billion rubles) are the main ones in terms of turnover and number.

The sharing economy transforms economic agents and their approaches. Drivers of the development for the sharing economy are the following trends:

\footnotetext{
* Corresponding author: gluchih_p_1@mail.ru
} 
The rapid emergence of advanced technological capabilities, which, thanks to the innovativeness of entrepreneurs, become goods and services, in particular AI / ML; FinTech; Marketplaces; Blockchain; IoT, etc.

Formation of future technological markets. All key countries of the world are making bets - choosing state priorities for technological development, making serious efforts and using resources to take leadership positions in the future, partly owning to the development of serial entrepreneurship.

Transformation of traditional markets as a result of platformization ("uberization" of the economy) and the development of markets for Internet services. A process of changing traditional markets takes place due to applying another method of selling products $-\mathrm{a}$ platform business model [1]. All 10 most visited sites in Russia work using the platform business model (vk.com, yandex.ru, youtube.com, mail.ru, google.ru, ok.ru, google.com, avito.ru, instagram.com, facebook.com). The platform acts as a service that allows you to combine the interests of buyers and sellers in order to exchange goods, services and information with minimal costs. For example, thanks to Avito and Yula, online ad services, some even new products can be bought cheaper than in the store, since sellers do not incur the costs for creating and maintaining their own website, etc. The example of Uber company, which created an Internet service directly connecting passengers and drivers in the traditional taxi market, turned out to be indicative. Thus, the existing market was forced to transform significantly. Many classic carrier companies also had to switch to the platform business model (for example, in Russia it is RuTaxi ("Vezet", "Leader"), Fasten ("Taxi Saturn", RedTaxi) . It is very likely that this trend will continue and platforms will appear in other existing industries taking consumers away from current companies. The growing need of individuals and entrepreneurs to spend less and earn more especially in the context of stagnating incomes is nowadays evident. The greatest growth in the popularity of sharing services in developed countries was during the economic crisis that began in 2007. With the current recession triggered by COVID-19 and related restrictions, the demand for facilities and business opportunities for these services has revived.

For micro-entrepreneurs, the sharing economy poses new challenges and threats. The sharing economy is viewed as a socio-economic concept that influences the behavior of a significant number of modern individuals. The evolution of theory and practice allows to expand the concept with several more research areas including consideration of the particular entrepreneurs' role in activating the sharing economy. The growing maturity of the sharing economy markets leads to the transformation of the motives and patterns for the use of these services. Whereas previously the dominant incentive for entrepreneurs to use sharing services was the opportunity to save money, recently they have been increasingly interested in the wide possibilities and flexibility of business models for entrepreneurial activity, including the representatives of the smallest but popular form of business - microentrepreneurs.

The development of the sharing economy has a number of controversial consequences. On the one hand, Internet platforms that are spreading among entrepreneurs increase entrepreneurial activity, including providing an easier entry into entrepreneurial activity for the population. On the other hand such Internet services stimulate the expansion of the shadow economy in Russia (it continued to grow, according to World Bank researchers, from about $12.5 \%$ in 2000 to over $20 \%$ in 2016). On the one side, consumers are increasingly opting for temporary consumption instead of purchasing durable goods. This behavior pattern should lead to a decrease in demand for new goods and services. This will lead to a new form of overproduction and redistribution of income from entrepreneursproducers in favor of entrepreneurs-owners or participants of Internet platforms. On the other side, there is an inverse and often overlooked determinant of behavior - mental accounting, as described by the Nobel laureate in economics Richard Thaler [2]. For 
example, a part of the population may show entrepreneurial behavior and buy a car not only for personal use but also consider it as an entrepreneurial opportunity to make money by renting it out through sharing services.

Insufficiently studied models of micro-entrepreneurs' behavior in Internet platform markets are becoming widespread. The importance of sharing economy is not so obvious a balanced and interdisciplinary response is required to the challenges that it poses. In particular, the following questions are being actualized: What opportunities and risks does the development of the sharing economy entail for entrepreneurs including beginners? What effect does it have on traditional businesses? How should regulation develop in this area?

Revision of the approach to small business as a factor of economic stability in an emergency environment is needed. A gradual revision of the small business role in Russian economy is being performed nowadays. Thus, the report of the Higher School of Economics criticizes the approach used in the national project when small business is interpreted as a condition of "ensuring employment of the population" or an instrument of sustainability for "regional labor markets." The report proposes to strengthen its role and position it as a factor of GDP stability (moreover, a dynamic factor). This approach can be very beneficial especially in a recession. According to the Institute of Business Ombudsman, the consequences of COVID-19 spread affected about 4.17 million companies and individual entrepreneurs out of 6.05 million (up to $67 \%$ of enterprises and individual entrepreneurs). At the same time, small and medium-sized businesses are characterized by a decline in "revenue by more than 30\%" which will lead to the bankruptcy of a significant number of micro-entrepreneurs.

Thus, it is required to assess the reliability of scientific knowledge about the motives for the widespread dissemination of new entrepreneurial behavior models in the sharing economy as well as their consequences for the entrepreneurial ecosystem. Therefore, the purpose of the article is to identify and assess the development of theoretical and methodological approaches to micro-entrepreneurs' behavior models in Internet platforms markets and the consequences of their spread for the sustainability of micro-entrepreneurs themselves and the national entrepreneurial ecosystem in the context of the developing sharing economy.

\section{Materials and research methods for studying micro- entrepreneurs on Internet platforms}

The methodological basis of the study is the systemic and socio-economic approaches, which, based on the dialectical study of the contribution of small entrepreneurship to the social well-being of the population and the economic growth of the country, will make it possible to identify, analyze, classify and evaluate the development of theoretical and methodological approaches to behavior models of micro-entrepreneurs in Internet platform markets and the consequences of their spread. The socio-economic approach is applied through the tools of economic and sociocultural analysis. In contrast to the traditional economic one, this approach presupposes the priority not only of economic, but also of socio-psychological factors, which together influence entrepreneurial decisions. Also, the assessment uses an approach when the main object of research is the individual as a typical representative (in the study, such an object is Russian micro-entrepreneur). This approach is gaining popularity, claiming to be the mainstream direction of modern economic thought. It is based on economic personalism, focusing on certain aspects of economic theory, behavioral economic theory, institutional economics (evolutionary and institutional economics), as well as psychology (cognitive, social and psychology of activity), the philosophy of neopositivism, existentialism. 
To collect and summarize the theoretical and methodological thesis, which foreign and domestic studies on the economy of shared consumption and models of entrepreneurial behavior contain, general theoretical methods of scientific knowledge were used in the resaerch, such as the dialectical method (study of entrepreneurial behavior patterns in their dynamic development), causal analysis (the relationship and interdependence of the sharing economy, Internet platform markets, entrepreneurial behavior patterns), methods of deduction and induction, analysis and synthesis.

\section{Analysis of the studies on micro-entrepreneurs on Internet platforms}

The significance of the considered problem relates to the non-obviousness and ambiguity of the consequences of the sharing economy, which are manifested in the spread of entrepreneurial behavior patterns in Internet platform markets, due to the lack of a scientific assessment for their impact on the social and economic development of the country. The problem is investigated in 2 closest scientific aspects:

First, the study of the consequences of the sharing economy (sharing economy, sharing, and sometimes collaborative economy are also commonly used as the most similar terms). The creators of the "shared consumption" concept were American researchers Botsman R., Rogers R. (2010) [3]. This concept received a stormy and in the overwhelming majority at first extremely positive response, which was subsequently actively criticized and developed:

Also, the studies on people's motivation to participate in shared consumption (Lamberton C. P., Rose R. L. (2012) [4], Hamari J., Sjöklint M., Ukkonen A. (2016) [5]). They are of great interest in terms of understanding the reasons for the spread of sharing patterns. This is how the mutual hierarchy of the participation motives in the sharing economy was revealed. However, in this scientific subdirection, the features of the entrepreneurial perception of the sharing economy and motives for spreading remain unexplored.

The studies on the essence and possibilities of the sharing economy. The modern understanding and content of the sharing economy is disclosed, for example by Barnes S. J. and Mattsson J. (2017) [6]. They revealed that the most important for consumers are the following opportunities of the sharing economy: economic, environmental and social benefits, as well as the status of belonging to a certain user community. Some popular science and many national publications are often limited only to the descriptive nature of the sharing economy, considering it as an external condition that affects the object under study (for example, Zezin M.B., Vorotnikov A.M. (2018) [7], etc.). Despite the titles of the publications, in most cases, the question of its intensity degree in Russia remains unclear.

Investigation of the sharing economy potencial in solving specific industry problems. This is a research area which is rather far off the research topic, but very popular both with foreign and national authors. It concerns attempts of the sharing economy to influence definite sectors of the national economy (for example, Ozanne LK, Ballantine PW (2010) [8]; Albinsson PA, Perera BY ( 2012) [9]; Filatova N.G. (2018) [10]). To a greater extent, such studies relate to industries that are most susceptible to its influence.

Then, the behavior of individuals on Internet platforms of the sharing economy. The closest foreign study on the problem is the research project No. 732117 , funded by the EU (Horizon 2020) - "Ps2Share: Participation, Privacy, and Power in the Sharing Economy". It analyzes the expectations of Internet platform users in order to identify the principles of the sharing economy, also for further development of new Internet platforms (StanoevskaSlabeva K., Lenz-Kesekamp V., Suter V. (2017) [11]). Despite the closeness of the research 
area, this project, unfortunately, does not consider entrepreneurs as a special group of platform participants, does not analyze their behavior in terms of cognitive distortions.

Thus, the study of the sharing economy has been actively developing abroad and in Russia, however, the consequences of the spread of sharing economy to such an object as entrepreneurs remain underestimated.

Secondly, the study of entrepreneurial behavior. It is stated that the concepts "entrepreneurial models" and "models of entrepreneurs' are vague despite attempts to understand and compare them. In some studies, the phrase "business behavior models" can mean other aspects, for example, types of entrepreneurship behavior (Ignatova I.V. (2011) [12]; Plenkina V.V., Osinovskaya I.V. [13]). Other researchers are trying to distinguish between these concepts (Doroshenko S. V. (2018) [14]). Therefore, we have to admit that a sufficiently sustainable term "entrepreneurs' behavior model" has not been formed in Russian scientific practice yet.

There are some researches in the field of entrepreneurial behavior based on the use of Internet platforms. However, only a few studies deal with particular cases of using Internet platforms. So, Tagarov B.Zh. (2019) [15] examines innovative forms of production, for which the availability of Internet platforms is important. Ermakova E.A. and Kudryavtsev K.A. (2014) [16] showed the importance of Internet platforms for the cooperation of companies that accept the principle of open innovation.

Also, the study on the importance of new technological opportunities for creating and developing a business for micro-entrepreneurs should be mentioned. The greatest risks of technological change are experienced by the most massive segment of the smallest entrepreneurship forms (micro-entrepreneurs, self-employed). Researchers Chew H.E., Ilavarasan V.P. and Levy M.R. identified that it is valuable for micro-entrepreneurs to use gadgets they already know, such as mobile phones, in particular, for the maintenance of micro-entrepreneurs' business networks [17]. No similar studies on the importance of micro-entrepreneurs' use of Internet platforms have been conducted yet.

\section{Conclusion}

1. The completeness and depth of the studies review on this issue allow us to conclude that the research is devoted to a relevant topic which is poorly studied in the Russian segment of scientific literature. Some aspects of this problem are separately studied by foreign and, in some cases, national experts.

2. In Russian scientific practice, a sustainable term "entrepreneurs' behavior model" has not been formed yet. But at the same time, despite the gradual growth of interest, these works did not identify or describe entrepreneurial behavior models in Internet platform markets specifically, moreover, they did not assess the consequences of their spread in Russian conditions, which requires separate studies.

3. The need for a complex study on the consequences of the use of Internet platforms and the identification of the consequences for such behavior models among microentrepreneurs, is actualized, taking into consideration their greater financial instability. If we take into account all micro business making such a choice, including those carrying out activities without state registration, then the cumulative consequences can be very significant for the development of the entrepreneurial ecosystem and the entire national economy.

4. The real contribution of small entrepreneurs, who are involved in the sharing economy, in solving certain strategic tasks in Russia is increasing:

- the national project "Housing and Urban Environment": the Moscow Government estimated "the Moscow car-sharing fleet in 2018 at 15 thousand cars"; 
- the national project "Ecology": in Moscow, due to bike sharing in 2018, there was "a reduction in carbon dioxide emissions by 40 tons";

- the national project "Digital Economy": the Russian crowd-funding market reached 11 billion rubles, a significant part of this money subsidized innovative entrepreneurial projects.

5. Evaluation of opportunities for the development of small business under the influence of Internet platforms of the sharing economy has not been sufficiently studied. For example, the volume of transactions of the sharing economy in 2016 in the EU reached 28 billion EUR, only 3.6 billion of which are the income of the platform companies themselves. The rest was earned by entrepreneurs and households. To assess the contribution of national small businesses and micro-entrepreneurs to the achievement of the level stated in the Decree on the National Development Goals in Russia until 2030 "increase in the number of employed in small and medium-sized businesses, including individual entrepreneurs and self-employed, to 25 million people" - a separate complex study is required.

\section{Acknowledgements}

The research was carried out at the expense of a grant from the Russian Science Foundation (project no. 20-78-00063).

\section{References}

1. E. L. Andreeva, P. L. Glukhikh, Y. G. Myslyakova, Upravlenets-The manager, 9, 6 (2018)

2. R.H. Thaler, Marketing Science, 4, 3 (1985)

3. R. Botsman, R. Rogers, What's Mine Is Yours: The Rise of Collaborative Consumption (2010)

4. C. P. Lamberton, R. L. Rose, Journal of Marketing, 76, 4 (2012)

5. J. Hamari, M. Sjöklint, A. Ukkonen, JASIST, 67, 9 (2016)

6. S. J. Barnes, J. Mattsson, Technol. Forecast. Soc. Change, 118, 281 (2017)

7. M. Zezin, A. Vorotnikov, Journal of economic studies, 4, 5 (2018)

8. L.K. Ozanne, P.W. Ballantine, Journal of Consumer Behaviour, 9, 6 (2010)

9. P.A. Albinsson, B.Y. Perera, Journal of Consumer Behaviour, 11, 4 (2012)

10. N.G. Filatova, Economics of sustainable development, 35, 3, (2018)

11. K. Stanoevska-Slabeva, V. Lenz-Kesekamp, V. Suter, SSRN Electronic Journal (2017)

12. I.V. Ignatova, Tyumen State University Herald, 8, 105 (2011)

13. V.V. Plenkina, I.V. Osinovskaja, Management of economic systems: scientific electronic journal, 74, 2 (2015)

14. S.V. Doroshenko, Russia: development trends and prospects, 13-1 (2018)

15. B.Zh. Tagarov, Journal of international economic affairs, 9, 2 (2019)

16. E. A. Ermakova, K. A. Kudryavtsev, Innovations, 183, 1 (2014)

17. H.E. Chew, V.P. Ilavarasan, M.R. Levy, Information technology for development, 21, 4 (2015) 